\title{
Vertebroplasty and kyphoplasty: a comparative review of efficacy and adverse events
}

\author{
Todd McCall $\cdot$ Chad Cole $\cdot$ Andrew Dailey
}

Published online: 12 January 2008

(C) Humana Press 2008

\begin{abstract}
Vertebroplasty and kyphoplasty have become common surgical techniques for the treatment of vertebral compression fractures. Vertebroplasty involves the percutaneous injection of bone cement into the cancellous bone of a vertebral body with the goals of pain alleviation and preventing further loss of vertebral body height. Kyphoplasty utilizes an inflatable balloon to create a cavity for the cement with the additional potential goals of restoring height and reducing kyphosis. Vertebroplasty and kyphoplasty are effective treatment options for the reduction of pain associated with vertebral body compression fractures. Biomechanical studies demonstrate that kyphoplasty is initially superior for increasing vertebral body height and reducing kyphosis, but these gains are lost with repetitive loading. Complications secondary to extravasation of cement include compression of neural elements and venous embolism. These complications are rare but more common with vertebroplasty. Vertebroplasty and kyphoplasty are both safe and effective procedures for the treatment of vertebral body compression fractures.
\end{abstract}

Keywords Vertebroplasty · Kyphoplasty

\section{Introduction}

In the past two decades, vertebroplasty and kyphoplasty have emerged as surgical options that play a central role

T. McCall · C. Cole $\cdot$ A. Dailey $(\bowtie)$

Department of Neurosurgery, University of Utah, $175 \mathrm{~N}$.

Medical Drive, Salt Lake City, UT 84132, USA

e-mail: andrew.dailey@hsc.utah.edu in the treatment of vertebral compression fractures. Before the common use of vertebroplasty and kyphoplasty, the principal surgical option for treatment of compression fractures was decompression and fusion. However, surgical fixation frequently failed in elderly patients because of osteopenia [1]. Vertebroplasty was first introduced in 1987 by Galibert et al. [2], who successfully treated seven patients who had painful vertebral angiomas. Since then, the use of vertebroplasty has expanded to include treatment of osteoporotic compression fractures [3, 4], traumatic compression fractures $[5,6]$, and metastatic compression fractures [7, 8]. Osteoporotic compression fractures are now the most common indication for this procedure.

Vertebroplasty involves the percutaneous injection of cement, such as polymethylmethacrylate (PMMA), directly into the cancellous bone of a vertebral body with the goal of alleviating pain associated with a vertebral compression fracture and preventing further loss of vertebral body height or progression of kyphotic deformity. Kyphoplasty was introduced later as a modification of vertebroplasty in which a balloon tamp is inflated in the vertebral body to compress the cancellous bone and create a cavity. Theoretically, the cavity allows the cement to be injected under less pressure and minimizes extravasation. Additional goals of kyphoplasty include restoring vertebral body height and reducing kyphosis [9]. Since the inception of these procedures, a vast body of literature has been generated in an attempt to evaluate and compare them. Although there have been no published results of randomized controlled trials comparing vertebroplasty and kyphoplasty, recent systematic reviews help illustrate the similarities and differences of the two procedures with regards to treatment efficacy and complication risks. 


\section{Vertebral compression fractures}

A $15 \%$ loss of vertebral body height constitutes a vertebral compression fracture. The leading cause of vertebral compression fractures is osteoporosis, with an estimated annual incidence of 700,000 osteoporotic vertebral body compression fractures [10]. Twenty-six percent of women older than 50 years have a vertebral compression fracture [11], and the prevalence increases to $40 \%$ by the age of 80 years [12].

Osteoporotic vertebral compression fractures have become a major national health issue because of their high incidence, increasing associated costs [13], and deleterious sequelae. An estimated $84 \%$ of vertebral compression fractures are associated with pain [10]. Acute pain typically lasts approximately 4-6 weeks, with the pain occurring axially and correlating with the level of fracture. Activity aggravates the pain whereas lying down or sitting alleviates the pain. Point tenderness is a common finding on examination but is not present in $10 \%$ of cases and therefore should not be considered a requisite finding for surgical intervention [14]. Chronic pain occurs in one-third of vertebral compression fractures and is more likely to ensue when one level is severely collapsed or multiple levels are involved $[15,16]$. Loss of vertebral body height, thoracic kyphosis, and pain can also contribute to impaired pulmonary function, with the severity of pulmonary function decline correlating with the severity of spinal column deformity $[17,18]$. Other side effects of vertebral compression fracture include impaired mobility, limited exercise tolerance, chronic depression, and an increased likelihood of death [19].

Medical therapies for vertebral compression fractures include analgesics, bed rest, bracing, and rehabilitation [20, 21]. In patients with osteoporosis, weight-bearing exercise is crucial in the prevention of disease progression [22], and therefore bed rest can be counterproductive in the long run. Medical treatment of osteoporosis includes calcium supplements, vitamin $\mathrm{D}$, hormone replacement, and bisphosphonates [23]. Of note, none of these conservative therapies help restore loss of height or reduce kyphotic deformity [21].

\section{Patient selection for vertebroplasty and kyphoplasty}

Patients likely to benefit from vertebroplasty or kyphoplasty have a history of pain that correlates well with the level of a recent compression fracture. If a patient has multiple adjacent compression fractures, radiographic studies are helpful for identifying which level(s) should be treated. A T2-weighted magnetic resonance imaging or STIR sequence with magnetic resonance imaging will demonstrate increased signal intensity associated with edema in recent fractures [24]. A bone scan can also reveal more recent fractures, and increased activity is highly prognostic of a clinical response to vertebroplasty with a positive predictive value of $93 \%$ [25]. The use of computed tomography may also be helpful to determine the integrity of the posterior cortical wall and pedicle sizes. If the pedicles are small, the surgeon may more heavily consider a vertebroplasty with a smaller needle to avoid using the larger trocar and facing an increased risk of pedicle violation with kyphoplasty [15]. Potential contraindications to surgery include uncorrected coagulopathy, active infection, spinal canal compromise, radiculopathy, posterior vertebral body cortical fractures, and severe $(>75 \%)$ vertebral body collapse [26-30].

\section{Technical aspects}

The principal concerns when performing a vertebroplasty or kyphoplasty are proper placement of the needle or trocar for injection of the cement and avoiding extravasation of the cement, which can lead to compression of neural elements or venous embolism. Fluoroscopy is required for insertion of the trocar, with a goal of the trocar being placed in the anteromedial portion of the vertebral body. The results of both clinical [31] and ex vivo biomechanical studies $[32,33]$ suggest that a unipedicular approach can be as effective as a bipedicular approach. A transpedicular approach is reasonable if the pedicles are at least $4-5 \mathrm{~mm}$ wide. If the pedicles are too small to cannulate, as frequently occurs above T8, a lateral extrapedicular trajectory can be used. After the location of the trocar is confirmed, some authors prefer to use antecedent venography with contrast before the injection of cement to avoid a venous embolism [34], while others have concluded that this maneuver does not help avoid complications [14, 35]. If there is concern about venous or transcortical extravasation, the trocar may be moved or the cement may be allowed to solidify more before it is injected. The cement should be injected under live fluoroscopy and halted once the cement enters the posterior third of the vertebral body.

Several options are now available for use as a cement or filling material. Desirable characteristics for a filling material include good biocompatibility, adequate biomechanical strength and stiffness, and radiopacity. PMMA has been used for several decades in orthopedic procedures and it is the most commonly employed substance for filling material. Several PMMA cements have been marketed, including Cranioplastic (CMW, Blackpool, England), Osteobond (Zimmer, Warsaw, IN), Simplex P (StrykerHowmedica-Osteonics, Rutherford, NJ), and Fixos (Transysteme, Nimes, France). Biomechanical studies have 
demonstrated that Simplex P [36] and Cranioplastic [37] do not restore vertebral body stiffness, but strength is increased compared with prefracture values. Although differences in biomechanical properties such as compressive strength and modulus do exist between different PMMA preparations, these differences do not appear to be clinically relevant [38-40]. Alternatives to PMMA with similar biomechanical properties for strength and stiffness include calcium sulfate cement [41] and calcium phosphate cement [42-44]. BoneSource (Tryker-HowmedicaOsteonics, Rutherford, NJ), a hydroxyapatite cement, results in significantly less vertebral body strength than PMMA cements in ex vivo biomechanical studies of both vertebroplasty [37] and kyphoplasty [36]. Orthocomp (Orthovita, Malvern, PA), a bioactive glass cement that is naturally radiopaque, has better compressive strength and modulus than PMMA cements, suggesting that less Orthocomp would be required for mechanical stabilization of a fracture than a PMMA cement $[38,45]$.

\section{Biomechanics}

Vertebroplasty and kyphoplasty have been directly compared in an ex vivo model of osteoporotic cadaveric fractured vertebral bodies under repetitive loading conditions [46]. Initially after the procedures, patients in the kyphoplasty group had a significantly better mean height restoration of $2.7 \mathrm{~mm}$, compared with $0.7 \mathrm{~mm}$ with vertebroplasty. The height restoration with kyphoplasty represented a return to $97 \%$ of the original height. A separate ex vivo biomechanical study of kyphoplasty [36] also found a $97 \%$ reversal with kyphoplasty, compared with $30 \%$ with vertebroplasty. However, the initial gains measured in the study by Kim et al. [46] were lost after cyclic loading, with patients in the kyphoplasty group losing an average of $4.2 \mathrm{~mm}$ compared with $1.1 \mathrm{~mm}$ with vertebroplasty. The authors hypothesized that the repetitive loading crushes the weak cancellous bone between the endplates and cement bolus formed with kyphoplasty. In contrast, in vertebroplasty, the cement is injected under more pressure, allowing it to interdigitate in the cancellous bone and form a continuous cement column between endplates and thus better resist further compression. This hypothesis is consistent with the observation that vertebral bodies had a higher compression stiffness after vertebroplasty as compared to kyphoplasty [46]. Although these ex vivo studies do not exactly replicate a clinical situation, they clearly illustrate the need for long-term monitoring of patients to determine whether gains in vertebral height and kyphotic deformity achieved with vertebroplasty or kyphoplasty are durable.

\section{Clinical efficacy}

Criteria that have been used for determining the efficacy of vertebroplasty and kyphoplasty include reduction of pain, increase of patient function, and the restoration of vertebral height or spinal column alignment (Fig. 1). No randomized controlled trials have been performed to compare vertebroplasty directly with kyphoplasty. Numerous retrospective
Fig. 1 Preoperative (a) and postoperative (b)

roentgenograms of a 63-yearold patient who underwent kyphoplasty of a T12 compression fracture. The anterior vertebral height increased $4 \mathrm{~mm}$ and the kyphotic deformity decreased $5.6^{\circ}$
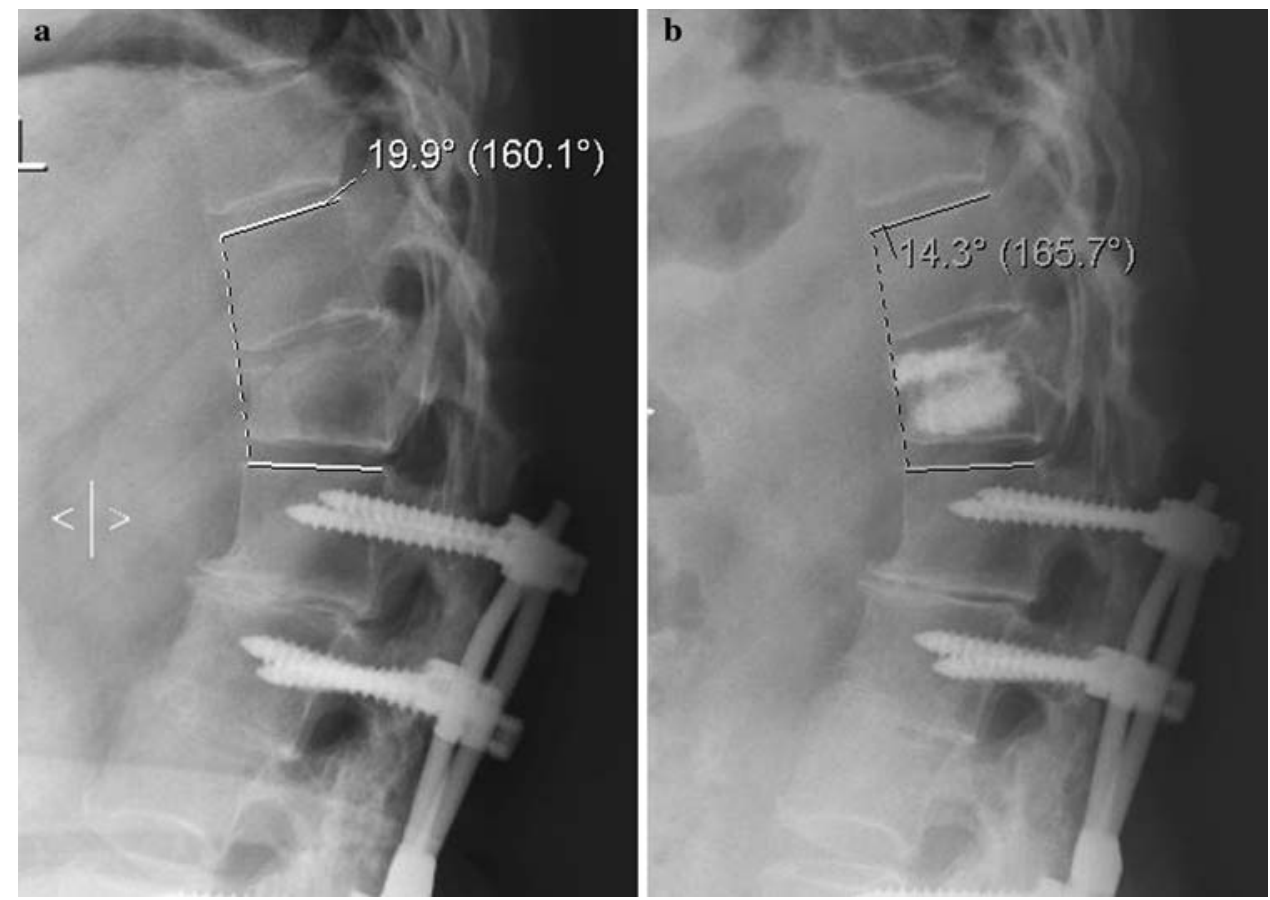
and prospective studies, including non-randomized comparative studies, have been undertaken. Systematic reviews of the literature have also recently been published that provide pooled data for an indirect comparison between vertebroplasty and kyphoplasty.

Taylor et al. [47] published a comparative systematic review of vertebroplasty and kyphoplasty in cases of vertebral body fractures due to osteoporosis or neoplasm that included one prospective study comparing vertebroplasty to medical care, one prospective and two retrospective studies comparing balloon kyphoplasty to medical care, one prospective study comparing the two procedures, and 70 case series. In the pooled case series data comprising 4,861 fractures treated by vertebroplasty and 1,070 fractures treated by kyphoplasty, a similar significant reduction of pain was achieved for vertebroplasty, with up to 5 years of follow-up, and kyphoplasty, with up to 2 years of followup. Kyphoplasty significantly improved functional capacity measured by the Oswestry Disability Score and Index of Back Function; reported outcomes with a validated instrument of patient function are lacking for vertebroplasty. Furthermore, kyphoplasty improved quality of life in six of eight Short-Form 36 domains reported by patients. Vertebroplasty also improved quality of life in three of four studies, but results could not be pooled because different outcome measures were used. Compared with medical therapy, kyphoplasty was superior for improving both pain and patient function, whereas vertebroplasty improved patient function but not pain. In the one study that directly compared vertebroplasty with kyphoplasty, the authors found a similar level of pain relief between the two procedures as measured by a Visual Analog Scale, but there was a notable selection bias in application of the procedures, with more severe compression fractures receiving kyphoplasty [48]. In comparative studies [48, 49] and case series, kyphoplasty resulted in significant improvement of vertebral body height and kyphotic deformity. Pooled case series data also demonstrated improved vertebral height and kyphotic angle with vertebroplasty.

A second systematic review of vertebroplasty and kyphoplasty encompassing 69 clinical studies was performed by Hulme et al. [50]; it included 4,456 vertebroplasty procedures and 1,624 kyphoplasty procedures. For a study to be included in the analysis, at least $80 \%$ of the treated vertebral compression fractures had to be related to osteoporosis. A comparable percentage of patients noted at least "some pain relief" with vertebroplasty (87\%) and kyphoplasty (92\%). Follow-up observation was short $(<1$ year) in most studies included in the analysis, but pain relief was persistent in one retrospective study with 1518 months of follow-up [4]. What patient or surgical factors correlate with successful pain relief have yet to be elucidated. Physical function and disability scores improved after both procedures, although results could not be pooled because of the wide variety of scales employed. Qualitatively, vertebroplasty and kyphoplasty achieved a similar improvement in vertebral height if at presentation a mobile fracture or intravertebral cleft was present. In pooled data, the mean kyphotic angle restoration was $6.6^{\circ}$ for both procedures; however, $34 \%$ of kyphoplasty patients and $39 \%$ of vertebroplasty patients did not attain an improvement in vertebral height or kyphotic deformity. Some authors have suggested that restoration of vertebral height is dependent on the age of the fracture [9, 51], although this finding is not universal [16].

In summary, direct comparisons between vertebroplasty and kyphoplasty are not possible because of a lack of prospective data comparing the two approaches. Indirect comparisons suggest that vertebroplasty and kyphoplasty reduce pain comparably. Both procedures appear to improve patient function in most series, although available data usually cannot be pooled because of a wide variety of measurement scales. Vertebral height restoration and reduction of kyphotic deformity are also similar for both procedures.

Vertebroplasty and kyphoplasty may also be used for fractures due to neoplasm. In the limited number of case series that have exclusively addressed the application of vertebroplasty or kyphoplasty to vertebral body fractures resulting from cancer, the results have been similar to those for osteoporotic fractures. In a retrospective review of 56 patients with multiple myeloma or metastatic disease who underwent 65 vertebroplasty and 32 kyphoplasty procedures, $84 \%$ of patients had marked or complete pain relief with a short mean follow-up of 4.5 months [48]. A prospective series of 18 multiple myeloma patients who underwent 55 kyphoplasty procedures demonstrated improvement in Short Form-36 scores and a 34\% mean restoration of vertebral height.

\section{Adverse events}

The aggregate complication rates of vertebroplasty and kyphoplasty are small, ranging from $<2 \%$ when treating osteoporotic compression fractures to $10 \%$ of cases related to malignant tumors $[30,39,52,53]$. More serious complications of vertebroplasty and kyphoplasty result from extravasation of the cement into the epidural space. Compression of neural elements can lead to paralysis with involvement of the spinal cord [54] or radiculopathy with compromise of a neural foraman [55]. In one review, neurological complications were seen in $0.6 \%$ of vertebroplasty and $0.03 \%$ of kyphoplasty cases [50]. Cement may also flow into venous channels and ultimately lead to a pulmonary embolism [56-58], which is reported to occur in 0.6 and $0.01 \%$ of vertebroplasty and kyphoplasty cases, 
respectively [50]. Other complications include infection, bleeding, and rib fracture or pneumothorax in thoracic cases. Pedicle fractures may be a more frequent complication of kyphoplasty because of the larger trocar size [59]. Osteomyelitis is a rare complication that may require corpectomy [60].

The results of several studies have demonstrated a higher rate of extravasation with vertebroplasty than with kyphoplasty. An in vivo study demonstrated significantly less vascular and transcortical extravasation of injected contrast with kyphoplasty than with vertebroplasty [61]. In the systematic review by Taylor et al. [47], cement leakage was significantly higher with vertebroplasty $(40 \%)$ than with kyphoplasty (8\%), and $3 \%$ of vertebroplasty leaks were symptomatic whereas no kyphoplasty leaks were reported to be symptomatic. Hulme et al. [50] found similar rates of extravasation for vertebroplasty $(41 \%)$ and kyphoplasty (9\%), with subsequent clinical complications occurring in 3.9 and $2.2 \%$ of vertebroplasty and kyphoplasty cases, respectively.

The literature is inconclusive on the risk of increased adjacent level fracture after these procedures, with rates of adjacent level fractures varying widely for both vertebroplasty (8-52\%) and kyphoplasty (3-29\%) [62-67]. In contradistinction, kyphoplasty resulted in a decreased incidence of subsequent vertebral body fractures compared with medical therapy alone [47]. It is interesting that the occurrence of new fractures after the procedure is weighted toward the first 30 postoperative days [63, 67], making extrapolation of normalized annual fracture rates from data generated by short follow-up periods problematic. In general, the literature suggests that the new fracture rate is higher in patients after one of these procedures than in subjects with osteoporosis but no fractures [68, 69]. This comparison may not be justified, however, because the presence of one osteoporotic fracture can increase the risk of developing another fracture up to 12.6-fold [70] and therefore the observed fracture rate may reflect the natural history of the disease. The higher incidence of fractures in the early postoperative period could potentially be explained by increased patient activity and higher stress secondary to a diminished level of pain. Overall, the current data are inconsistent, and no firm conclusions can be reached concerning the risk of adjacent level fractures after vertebroplasty or kyphoplasty.

\section{Future directions}

Most clinical experience with vertebroplasty and kyphoplasty has been with compression fractures secondary to osteoporosis or neoplasm causing back pain, but the potential indications continue to be expanded. The use of these procedures in cases involving radicular leg pain instead of back pain due to vertebral compression fractures, severe vertebral body collapse, epidural disease impinging on the spinal canal, burst fractures, and cervical spine disease have been reported to a limited extent [71-75].

Vertebroplasty and kyphoplasty do not necessarily need to be used as stand-alone treatments, although that has usually been the case. Several exceptions have been presented however. For example, short-segment pedicle screw fixation has been augmented with PMMA in the setting of thoracolumbar fractures to help maintain kyphotic correction and minimize hardware failure by providing additional anterior column support [76, 77]. PMMA-augmented constructs may also decrease hardware failure by increasing pedicle screw pull-out strength [78]. Kyphoplasty has also been combined with radiosurgery to treat pathological compression fractures and avoid surgeries associated with greater morbidity [79].

\section{Conclusions}

Vertebroplasty and kyphoplasty are relatively new techniques for the treatment of pain caused by vertebral body compression fractures. Kyphoplasty differs from vertebroplasty in that a balloon is first inflated in the vertebral body to create a cavity into which cement is then injected under lower pressure. Theoretically, inflating the balloon can increase vertebral height and reduce kyphotic deformity, while injecting the cement under lower pressure can minimize cement extravasation. There are no randomized trials to compare the two procedures, and therefore the available data only allow for indirect comparisons. On the basis of systematic reviews of the literature, it appears that patients undergoing either procedure achieve a comparable reduction in pain. Biomechanical studies suggest that kyphoplasty may initially be more effective in improving vertebral height, but this effect is subsequently lost with repetitive loading. These findings are consistent with clinical studies, which have found little difference between the procedures for improvement of vertebral height or kyphotic deformity. Overall, complication rates for both procedures are low; however, vertebroplasty appears to have a higher rate of cement extravasation with associated pulmonary emboli and compression of neural elements. As the indications of vertebroplasty and kyphoplasty continue to expand, well-designed randomized trials comparing the two procedures directly are required to determine their relative strengths and weaknesses in different clinical scenarios.

Acknowledgment The authors thank Kristin Kraus for her editorial assistance in preparing this article. 


\section{References}

1. Dickman CA, Fessler RG, MacMillan M, et al. Transpedicular screw-rod fixation of the lumbar spine: operative technique and outcome in 104 cases. J Neurosurg 1992;77:860-70.

2. Galibert P, Deramond H, Rosat P, et al. Preliminary note on the treatment of vertebral angioma by percutaneous acrylic vertebroplasty. Neurochirurgie 1987;33:166-8.

3. McGraw JK, Lippert JA, Minkus KD, et al. Prospective evaluation of pain relief in 100 patients undergoing percutaneous vertebroplasty: results and follow-up. J Vasc Interv Radiol 2002;13:883-6.

4. Zoarski GH, Snow P, Olan WJ, et al. Percutaneous vertebroplasty for osteoporotic compression fractures: quantitative prospective evaluation of long-term outcomes. J Vasc Interv Radiol 2002; 13:139-48.

5. Atalay B, Caner H, Gokce C, et al. Kyphoplasty: 2 years of experience in a neurosurgery department. Surg Neurol 2005; 64(Suppl 2):S72-6.

6. Burton AW, Mendel E. Vertebroplasty and kyphoplasty. Pain Physician 2003;6:335-41.

7. Kaemmerlen $\mathrm{P}$, Thiesse $\mathrm{P}$, Jonas $\mathrm{P}$, et al. Percutaneous injection of orthopedic cement in metastatic vertebral lesions. N Engl J Med 1989;321:121.

8. Tschirhart CE, Finkelstein JA, Whyne CM. Optimization of tumor volume reduction and cement augmentation in percutaneous vertebroplasty for prophylactic treatment of spinal metastases. J Spinal Disord Tech 2006;19:584-90.

9. Lieberman IH, Dudeney S, Reinhardt MK, et al. Initial outcome and efficacy of "kyphoplasty" in the treatment of painful osteoporotic vertebral compression fractures. Spine 2001;26: 1631-8.

10. Cooper C, Atkinson EJ, O'Fallon WM, et al. Incidence of clinically diagnosed vertebral fractures: a population-based study in Rochester, Minnesota, 1985-1989. J Bone Miner Res 1992; 7:221-7.

11. Silverman SL. The clinical consequences of vertebral compression fracture. Bone 1992;13(Suppl 2):S27-31.

12. Melton LJ 3rd, Kan SH, Frye MA, et al. Epidemiology of vertebral fractures in women. Am J Epidemiol 1989;129:1000-11.

13. Riggs BL, Melton LJ 3rd. The worldwide problem of osteoporosis: insights afforded by epidemiology. Bone 1995;17: 505S-11S.

14. Gaughen JR Jr, Jensen ME, Schweickert PA, et al. Relevance of antecedent venography in percutaneous vertebroplasty for the treatment of osteoporotic compression fractures. Am J Neuroradiol 2002;23:594-600.

15. Burton AW, Rhines LD, Mendel E. Vertebroplasty and kyphoplasty: a comprehensive review. Neurosurg Focus 2005;18:e1.

16. Phillips FM, Ho E, Campbell-Hupp M, et al. Early radiographic and clinical results of balloon kyphoplasty for the treatment of osteoporotic vertebral compression fractures. Spine 2003;28: 2260-7.

17. Leech JA, Dulberg C, Kellie S, et al. Relationship of lung function to severity of osteoporosis in women. Am Rev Respir Dis 1990;141:68-71.

18. Schlaich C, Minne HW, Bruckner T, et al. Reduced pulmonary function in patients with spinal osteoporotic fractures. Osteoporos Int 1998;8:261-7.

19. Kado DM, Browner WS, Palermo L, et al. Vertebral fractures and mortality in older women: a prospective study. Study of Osteoporotic Fractures Research Group. Arch Intern Med 1999; 159:1215-20.

20. Rapado A. General management of vertebral fractures. Bone 1996;18:191S-6S.
21. Reginster J, Minne HW, Sorensen OH, et al. Randomized trial of the effects of risedronate on vertebral fractures in women with established postmenopausal osteoporosis. Vertebral Efficacy with Risedronate Therapy (VERT) Study Group. Osteoporos Int 2000; 11:83-91.

22. Palombaro KM. Effects of walking-only interventions on bone mineral density at various skeletal sites: a meta-analysis. J Geriatr Phys Ther 2005;28:102-7.

23. Khosla S, Riggs BL. Treatment options for osteoporosis. Mayo Clin Proc 1995;70:978-82.

24. Baker LL, Goodman SB, Perkash I, et al. Benign versus pathologic compression fractures of vertebral bodies: assessment with conventional spin-echo, chemical-shift, and STIR MR imaging. Radiology 1990;174:495-502.

25. Maynard AS, Jensen ME, Schweickert PA, et al. Value of bone scan imaging in predicting pain relief from percutaneous vertebroplasty in osteoporotic vertebral fractures. Am J Neuroradiol 2000;21:1807-12.

26. Amar AP, Larsen DW, Esnaashari N, et al. Percutaneous transpedicular polymethylmethacrylate vertebroplasty for the treatment of spinal compression fractures. Neurosurgery 2001; 49:1105-15.

27. Barr JD, Barr MS, Lemley TJ, et al. Percutaneous vertebroplasty for pain relief and spinal stabilization. Spine 2000;25:923-8.

28. Cotten A, Boutry N, Cortet B, et al. Percutaneous vertebroplasty: state of the art. Radiographics 1998;18:311-23.

29. Peters KR, Guiot BH, Martin PA, et al. Vertebroplasty for osteoporotic compression fractures: current practice and evolving techniques. Neurosurgery 2002;51:S96-103.

30. Weill A, Chiras J, Simon JM, et al. Spinal metastases: indications for and results of percutaneous injection of acrylic surgical cement. Radiology 1996;199:241-7.

31. Kim AK, Jensen ME, Dion JE, et al. Unilateral transpedicular percutaneous vertebroplasty: initial experience. Radiology 2002;222:737-41.

32. Molloy S, Riley LH 3rd, Belkoff SM. Effect of cement volume and placement on mechanical-property restoration resulting from vertebroplasty. Am J Neuroradiol 2005;26:401-4.

33. Steinmann J, Tingey CT, Cruz G, et al. Biomechanical comparison of unipedicular versus bipedicular kyphoplasty. Spine 2005;30:201-5.

34. McGraw JK, Heatwole EV, Strnad BT, et al. Predictive value of intraosseous venography before percutaneous vertebroplasty. J Vasc Interv Radiol 2002;13:149-53.

35. Vasconcelos C, Gailloud P, Beauchamp NJ, et al. Is percutaneous vertebroplasty without pretreatment venography safe? Evaluation of 205 consecutives procedures. Am J Neuroradiol 2002; 23:913-7.

36. Belkoff SM, Mathis JM, Deramond H, et al. An ex vivo biomechanical evaluation of a hydroxyapatite cement for use with kyphoplasty. Am J Neuroradiol 2001;22:1212-6.

37. Belkoff SM, Mathis JM, Jasper LE. Ex vivo biomechanical comparison of hydroxyapatite and polymethylmethacrylate cements for use with vertebroplasty. Am J Neuroradiol 2002;23:1647-51.

38. Jasper LE, Deramond H, Mathis JM, et al. Material properties of various cements for use with vertebroplasty. J Mater Sci Mater Med 2002;13:1-5

39. Jensen ME, Evans AJ, Mathis JM, et al. Percutaneous polymethylmethacrylate vertebroplasty in the treatment of osteoporotic vertebral body compression fractures: technical aspects. Am J Neuroradiol 1997;18:1897-904.

40. Mathis JM, Petri M, Naff N. Percutaneous vertebroplasty treatment of steroid-induced osteoporotic compression fractures. Arthritis Rheum 1998;41:171-5. 
41. Perry A, Mahar A, Massie J, et al. Biomechanical evaluation of kyphoplasty with calcium sulfate cement in a cadaveric osteoporotic vertebral compression fracture model. Spine J 2005; 5:489-93.

42. Tomita S, Kin A, Yazu M, et al. Biomechanical evaluation of kyphoplasty and vertebroplasty with calcium phosphate cement in a simulated osteoporotic compression fracture. J Orthop Sci 2003;8:192-7.

43. Tomita S, Molloy S, Jasper LE, et al. Biomechanical comparison of kyphoplasty with different bone cements. Spine 2004;29: 1203-7.

44. Wilke HJ, Mehnert U, Claes LE, et al. Biomechanical evaluation of vertebroplasty and kyphoplasty with polymethyl methacrylate or calcium phosphate cement under cyclic loading. Spine 2006;31:2934-41.

45. Belkoff SM, Mathis JM, Jasper LE, et al. The biomechanics of vertebroplasty. The effect of cement volume on mechanical behavior. Spine 2001;26:1537-41.

46. Kim MJ, Lindsey DP, Hannibal M, et al. Vertebroplasty versus kyphoplasty: biomechanical behavior under repetitive loading conditions. Spine 2006;31:2079-84.

47. Taylor RS, Taylor RJ, Fritzell P. Balloon kyphoplasty and vertebroplasty for vertebral compression fractures: a comparative systematic review of efficacy and safety. Spine 2006;31: 2747-55.

48. Fourney DR, Schomer DF, Nader R, et al. Percutaneous vertebroplasty and kyphoplasty for painful vertebral body fractures in cancer patients. J Neurosurg 2003;98:21-30.

49. Kasperk C, Hillmeier J, Noldge G, et al. Treatment of painful vertebral fractures by kyphoplasty in patients with primary osteoporosis: a prospective nonrandomized controlled study. J Bone Miner Res 2005;20:604-12.

50. Hulme PA, Krebs J, Ferguson SJ, et al. Vertebroplasty and kyphoplasty: a systematic review of 69 clinical studies. Spine 2006;31:1983-2001.

51. Berlemann U, Franz T, Orler R, et al. Kyphoplasty for treatment of osteoporotic vertebral fractures: a prospective non-randomized study. Eur Spine J 2004;13:496-501.

52. Chiras J, Depriester C, Weill A, et al. Percutaneous vertebral surgery. Technics and indications. J Neuroradiol 1997;24:45-59.

53. Mathis JM, Barr JD, Belkoff SM, et al. Percutaneous vertebroplasty: a developing standard of care for vertebral compression fractures. Am J Neuroradiol 2001;22:373-81.

54. Lee BJ, Lee SR, Yoo TY. Paraplegia as a complication of percutaneous vertebroplasty with polymethylmethacrylate: a case report. Spine 2002;27:E419-22.

55. Ratliff J, Nguyen T, Heiss J. Root and spinal cord compression from methylmethacrylate vertebroplasty. Spine 2001;26:E300-2.

56. Chen HL, Wong CS, Ho ST, et al. A lethal pulmonary embolism during percutaneous vertebroplasty. Anesth Analg 2002;95: 1060-2.

57. Jang JS, Lee SH, Jung SK. Pulmonary embolism of polymethylmethacrylate after percutaneous vertebroplasty: a report of three cases. Spine 2002;27:E416-8.

58. Tozzi P, Abdelmoumene Y, Corno AF, et al. Management of pulmonary embolism during acrylic vertebroplasty. Ann Thorac Surg 2002;74:1706-8.

59. Nussbaum DA, Gailloud P, Murphy K. A review of complications associated with vertebroplasty and kyphoplasty as reported to the Food and Drug Administration medical device related web site. J Vasc Interv Radiol 2004;15:1185-92.
60. Walker DH, Mummaneni P, Rodts GE Jr. Infected vertebroplasty. Report of two cases and review of the literature. Neurosurg Focus 2004;17:E6.

61. Phillips FM, Todd Wetzel F, Lieberman I, et al. An in vivo comparison of the potential for extravertebral cement leak after vertebroplasty and kyphoplasty. Spine 2002;27:2173-9.

62. Cortet B, Cotten A, Boutry N, et al. Percutaneous vertebroplasty in the treatment of osteoporotic vertebral compression fractures: an open prospective study. J Rheumatol 1999;26:2222-8.

63. Fribourg D, Tang C, Sra P, et al. Incidence of subsequent vertebral fracture after kyphoplasty. Spine 2004;29:2270-7.

64. Grados F, Depriester C, Cayrolle G, et al. Long-term observations of vertebral osteoporotic fractures treated by percutaneous vertebroplasty. Rheumatology (Oxford) 2000;39:1410-4.

65. Kim SH, Kang HS, Choi JA, et al. Risk factors of new compression fractures in adjacent vertebrae after percutaneous vertebroplasty. Acta Radiol 2004;45:440-5.

66. Lin EP, Ekholm S, Hiwatashi A, et al. Vertebroplasty: cement leakage into the disc increases the risk of new fracture of adjacent vertebral body. Am J Neuroradiol 2004;25:175-80.

67. Uppin AA, Hirsch JA, Centenera LV, et al. Occurrence of new vertebral body fracture after percutaneous vertebroplasty in patients with osteoporosis. Radiology 2003;226:119-24.

68. Lindsay R, Silverman SL, Cooper C, et al. Risk of new vertebral fracture in the year following a fracture. J Am Med Assoc 2001;285:320-3.

69. Perez-Higueras A, Alvarez L, Rossi RE, et al. Percutaneous vertebroplasty: long-term clinical and radiological outcome. Neuroradiology 2002;44:950-4.

70. Melton LJ 3rd, Atkinson EJ, Cooper C, et al. Vertebral fractures predict subsequent fractures. Osteoporos Int 1999;10:214-21.

71. Chung SK, Lee SH, Kim DY, et al. Treatment of lower lumbar radiculopathy caused by osteoporotic compression fracture: the role of vertebroplasty. J Spinal Disord Tech 2002;15:461-8.

72. Hentschel SJ, Burton AW, Fourney DR, et al. Percutaneous vertebroplasty and kyphoplasty performed at a cancer center: refuting proposed contraindications. J Neurosurg Spine 2005;2: 436-40.

73. Nakano M, Hirano N, Matsuura K, et al. Percutaneous transpedicular vertebroplasty with calcium phosphate cement in the treatment of osteoporotic vertebral compression and burst fractures. J Neurosurg 2002;97:287-93.

74. Peh WC, Gilula LA, Peck DD. Percutaneous vertebroplasty for severe osteoporotic vertebral body compression fractures. Radiology 2002;223:121-6.

75. Wetzel SG, Martin JB, Somon T, et al. Painful osteolytic metastasis of the atlas: treatment with percutaneous vertebroplasty. Spine 2002;27:E493-5.

76. Acosta FL Jr, Aryan HE, Taylor WR, et al. Kyphoplasty-augmented short-segment pedicle screw fixation of traumatic lumbar burst fractures: initial clinical experience and literature review. Neurosurg Focus 2005; 18:e9.

77. Cho DY, Lee WY, Sheu PC. Treatment of thoracolumbar burst fractures with polymethyl methacrylate vertebroplasty and shortsegment pedicle screw fixation. Neurosurgery 2003;53:1354-61.

78. Sarzier JS, Evans AJ, Cahill DW. Increased pedicle screw pullout strength with vertebroplasty augmentation in osteoporotic spines. J Neurosurg 2002;96:309-12.

79. Gerszten PC, Germanwala A, Burton SA, et al. Combination kyphoplasty and spinal radiosurgery: a new treatment paradigm for pathological fractures. Neurosurg Focus 2005;18:e8. 